\title{
Optimization of process parameters for synthesis of silica-Ni nanocomposite by design of experiment
}

\author{
A K PRAMANICK ${ }^{1}$, M K MITRA $^{1}, \mathbf{S}$ MUKHERJEE ${ }^{2}$, G C DAS $^{2}$ and B DUARI ${ }^{3, *}$ \\ ${ }^{1}$ Department of Metallurgical and Material Engineering, Jadavpur University, Kolkata 700 032, India \\ ${ }^{2}$ School of Material Science and Nano-Technology, Jadavpur University, Kolkata 700 032, India \\ ${ }^{3}$ Rustech Products Pvt. Ltd., Kolkata 700 045, India
}

MS received 4 April 2012; revised 12 January 2013

\begin{abstract}
The optimum combination of experimental variable, temperature, time of heat treatment under nitrogen atmosphere and amount of $\mathrm{Ni}$-salt was delineated to find out the maximum yield of nanophase $\mathrm{Ni}$ in the silica gel matrix. The size of $\mathrm{Ni}$ in the silica gel was found to be 34 and $45 \mathrm{~nm}$ for the two chosen compositions, respectively. A statistically adequate regression equation, within $95 \%$ confidence limit was developed by carrying out a set of active experiments within the framework of design of experiment. The regression equation is found to indicate the beneficial role of temperature and time of heat treatment.
\end{abstract}

Keywords. Sol-gel; Ni; design of experiments; nanocomposites.

\section{Introduction}

The synthesis and characterization of nanostructured materials has found importance world over, because of their novel properties and potential for applications in many fields. Good reviews on basic understanding are available (Gorla et al 1999; Gao and Bando 2002; Aldal et al 2005). Many methods have been used for synthesis of nanomaterials of which sol-gel technique is very versatile (Das et al 1990; Rao 1993; Mallick et al 2006). This technique has been exploited to synthesize metal-insulator nanocomposites. Insulator nanocomposites have possible applications in optical switches and single electron transistor (Yeshchenko et al 2008), fine soft magnetic materials (Tang et al 2004), microwave absorbing and shielding materials (Peng et al 2008), super paramagnet (Fonseca 2003), etc. The kinetics of reduction of the metal salts in silica gel matrix is widely studied. Detailed kinetic analysis for in situ reduction of transition metal salts in silica is reported (Basumallick et al 1999) and for understanding the mechanism of reduction and computation of the activation energy for silica-alumina gel matrix is also available (Mallick et al 2006). The amount of metal along with other morphological characterization influences the property (Granquivst and Hunderi 1977). However, very little work has been done on the quantitative relationship between the reduction of metal salts in silica powder as a function of experimental parameters, viz. temperature and time of reduction (Roy et al 2007). It was, therefore,

\footnotetext{
*Author for correspondence (bduari@yahoo.co.in)
}

thought to be worthwhile to find out such a quantitative relationship and this paper deals with the development of statistically adequate relationship within the framework of design of experiment.

\section{Experimental}

The temperature of reduction $\left(Z_{1}\right)$, time of reduction $\left(Z_{2}\right)$, amount of nickel chloride $\left(Z_{3}\right)$ were taken as the independent process parameters. As per the requirement of design of experiment, each parameter must have upper and lower levels. Table 1 summarizes the upper and lower levels chosen for this experiment. Thus, it required to make $2^{3}$ samples along with three replicates at the base level. First, a set of four gel samples were made. Each one with TEOS: $\mathrm{H}_{2} \mathrm{O}: \mathrm{C}_{2} \mathrm{H}_{5} \mathrm{OH}$ ratio of 1:1:2 by volume, respectively was prepared. A homogeneous solution was prepared with $1 \mathrm{~mL}$ of distilled water, containing $0.159 \mathrm{~g}$ of $\mathrm{NiCl}_{2}$ along with $50 \%$ excess glucose over stoichiometric requirement of complete reduction of $\mathrm{NiCl}_{2}, 5 \mathrm{~mL}$ of ethyl alcohol and $4 \mathrm{~mL}$ of distilled water. The solution was stirred thoroughly for getting a homogeneous solution. A second homogeneous solution of $5 \mathrm{ml}$ $\mathrm{C}_{2} \mathrm{H}_{5} \mathrm{OH}$ and $5 \mathrm{ml}$ tetraethyl orthosilicate (TEOS) was also prepared under constant magnetic stirring. The first solution was added dropwise to the second one under continuous stirring with a magnetic stirrer. The resulting solution was left for gelling at room temperature.

A second set of four gel samples were made similarly, with the same ratio of TEOS: $\mathrm{H}_{2} \mathrm{O}: \mathrm{C}_{2} \mathrm{H}_{5} \mathrm{OH}$ as mentioned earlier, but it contained double the amount of $\mathrm{NiCl}_{2}$ compared to that of the first set. 
Table 1. Upper and lower levels of process parameters.

\begin{tabular}{lcc}
\hline Parameter & Upper level & Lower level \\
\hline$Z_{1}$ & $900{ }^{\circ} \mathrm{C}$ & $700{ }^{\circ} \mathrm{C}$ \\
$Z_{2}$ & $8 \mathrm{~min}$ & $1 \mathrm{~min}$ \\
$Z_{3}$ & $0 \cdot 318 \mathrm{~g}$ & $0.159 \mathrm{~g}$ \\
\hline
\end{tabular}

A set of three gel samples for base level was made exactly the same way, with the same ratio of TEOS: $\mathrm{H}_{2} \mathrm{O}: \mathrm{C}_{2} \mathrm{H}_{5} \mathrm{OH}$, but each gel containing $0.2385 \mathrm{~g}$ of $\mathrm{NiCl}_{2}$.

The eight samples were then heat treated as per the temperature and time given in table 1 , in a tubular electrically heated furnace under constant flow of dry oxygen free nitrogen.

The reaction produced $\mathrm{HCl}$ vapour which was swept away from the reaction site and was bubbled through the gas absorbing towers containing double-distilled water, where $\mathrm{HCl}$ vapour was absorbed. $\mathrm{pH}$ of the resultant solution was measured from which the fraction of $\mathrm{NiCl}_{2}$ reduced was calculated and is summarized in table 2. Table 2 also contains data of three replicates each heat treated in $\mathrm{N}_{2}$ atmosphere at the base level of $800^{\circ} \mathrm{C}$ for a period of $41 / 2 \mathrm{~min}$.

Two typical heat treated samples were ground and passed through 400 mesh and XRD patterns of these were taken using $\mathrm{CuK} \alpha$ monochromatic radiation in Regaku make Ultima III, XRD instrument.

\section{Results and discussions}

This section basically involves two parts. The first part deals with the reduction of $\mathrm{NiCl}_{2}$ in the nanopores of silica gel to metallic $\mathrm{Ni}$ and its identification while the second part deals with the statistical analysis of the reduction data.

In situ reduction of $\mathrm{NiCl}_{2}$ in silica gel occurs as follows as reported elsewhere in detail

$$
\begin{aligned}
& \mathrm{C}_{6} \mathrm{H}_{12} \mathrm{O}_{6}=6 \mathrm{C}+6 \mathrm{H}_{2} \mathrm{O} \uparrow, \\
& \mathrm{C}+\mathrm{H}_{2} \mathrm{O}=\mathrm{CO} \uparrow+\mathrm{H}_{2} \uparrow, \\
& \mathrm{H}_{2}+\mathrm{NiCl}_{2}=\mathrm{Ni}+2 \mathrm{HCl} \uparrow .
\end{aligned}
$$

The nanoporous silica gel matrix plays a very important role in this in situ reduction. The first one is that the nanopores restrict the reduced metal to be in the nanometric dimension. Secondly, it is important to note that the reactions occur in nanopores simultaneously throughout the bulk of silica gel matrix, which make kinetics of reduction much faster. Thirdly, since the nanosized metal is entrapped in the silica matrix subsequently there is hardly any oxidation.

Figures 1 and 2 represent XRD patterns of the gel samples containing 5 and $10 \mathrm{wt} \% \mathrm{NiCl}_{2}$, respectively which were heat treated at $900{ }^{\circ} \mathrm{C}$ for $8 \mathrm{~min}$. Computed ' $d$ ' values are in good agreement with standard ' $d$ ' values of metallic Ni. Peaks corresponding to metallic $\mathrm{Ni}$ are indicated in both the figures.
Table 2. Fraction of $\mathrm{NiCl}_{2}$ reduced for different combinations of experimental variables.

\begin{tabular}{lccc}
\hline$Z_{1}\left(\right.$ in $\left.{ }^{\circ} \mathrm{C}\right)$ & $Z_{2}$ (in Min) & $Z_{3}($ in $\mathrm{gM})$ & Fraction $\mathrm{NiCl}_{2}$ reduced \\
\hline 900 & 8 & $0 \cdot 318$ & 0.980 \\
900 & 1 & $0 \cdot 318$ & 0.063 \\
900 & 8 & $0 \cdot 159$ & 0.982 \\
900 & 1 & $0 \cdot 159$ & $0 \cdot 066$ \\
700 & 8 & $0 \cdot 318$ & 0.577 \\
700 & 1 & $0 \cdot 318$ & 0.013 \\
700 & 8 & $0 \cdot 159$ & 0.634 \\
700 & 1 & $0 \cdot 159$ & 0.021 \\
800 & 4.5 & 0.238 & 0.620 \\
800 & 4.5 & 0.238 & 0.680 \\
800 & 4.5 & 0.238 & 0.700 \\
\hline
\end{tabular}

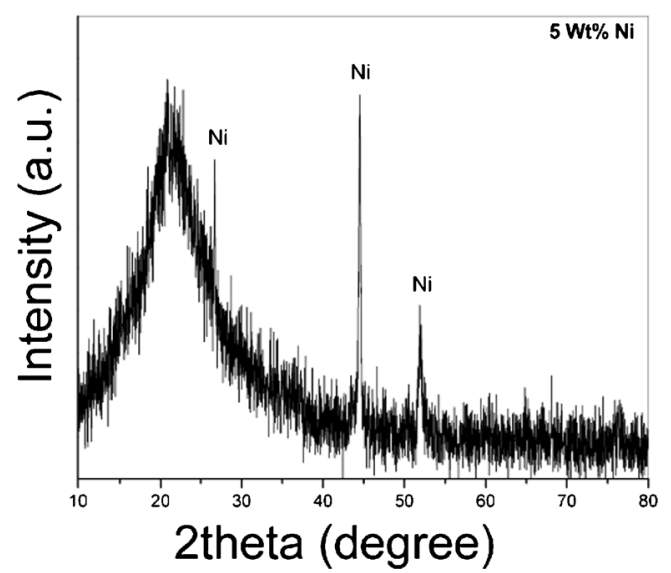

Figure 1. XRD pattern of sample containing $5 \mathrm{wt} \% \mathrm{Ni}$ heat treated at $900{ }^{\circ} \mathrm{C}$ for $8 \mathrm{~min}$ in nitrogen atmosphere.

The value of $\sin \theta / \lambda$ in each of samples (figures 1 and 2) for the hump is 0.116 , very close to 0.12 , which is attributed to amorphous silica (Warren and Biscal 1938). This is plausibly due to slow kinetics of crystallization of amorphous silica arising out of lower reduction temperature for a shorter period of time.

Scherrer formula (Cullity 1978) given below was used to compute the particle size of nickel

$$
t=0 \cdot 9 \lambda / B \cos \theta,
$$

where $t$ is the average particle size in $\AA, B$ the width of the peak at half-maximum in radian and $\lambda$ the wavelength of $\mathrm{X}$-ray in $\AA$.

The highest intensity peak in each case was used to compute the size of $\mathrm{Ni}$ which were $34 \mathrm{~nm}$ for $5 \mathrm{wt} \% \mathrm{Ni}-$ $\mathrm{SiO}_{2}$ composite and 46 for $10 \mathrm{wt} \% \mathrm{Ni}-\mathrm{SiO}_{2}$ composite, respectively.

Figure 3 shows clearly nanometric dimension of the nickel particles. From the inset observed, $d=0.21 \mathrm{~nm}$ matches reasonably well with the reported value of $d=0.203 \mathrm{~nm}$ of the metallic Ni. 


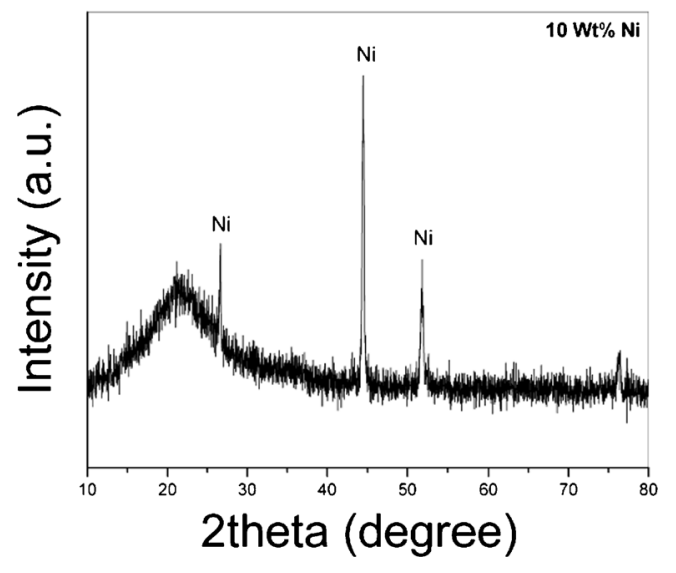

Figure 2. XRD pattern of sample containing $10 \mathrm{wt} \% \mathrm{Ni}$ heat treated at $900{ }^{\circ} \mathrm{C}$ for $8 \mathrm{~min}$ in nitrogen atmosphere.

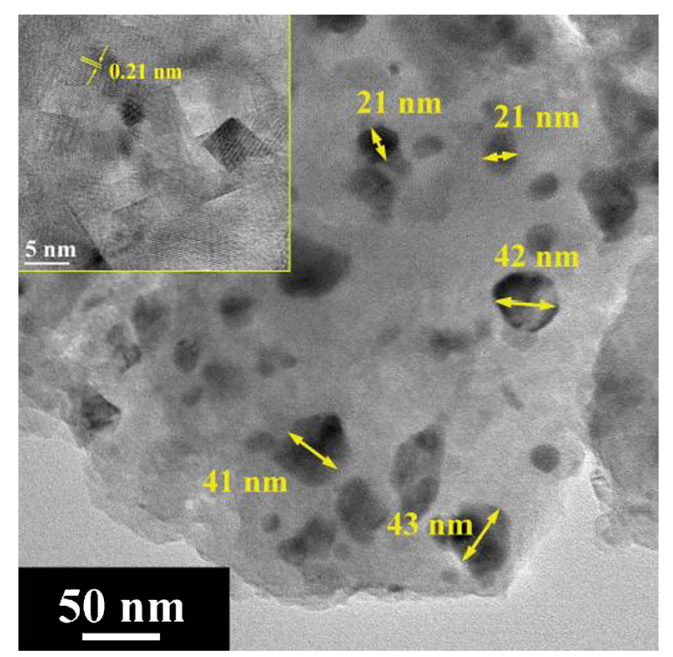

Figure 3. TEM image of sample containing $5 \mathrm{wt} \% \mathrm{Ni}$ heat treated at $900{ }^{\circ} \mathrm{C}$ for $8 \mathrm{~min}$ in nitrogen atmosphere and lattice image is included in inset.

Table 2 contains experimentally determined fraction of $\mathrm{NiCl}_{2}$ reduced for different combinations of experimental conditions along with three replicates at the base level.

Statistical analysis on reduction data was based within the framework of design of experiment:

Experimental variables $Z_{j}, j=1,2,3$ on natural scale, respectively representing temperature, time and weight of $\mathrm{NiCl}_{2}$ were converted to dimension less variables $x_{j}, j=1$, 2,3 such that $x_{j}=+1,-1$ and 0 , respectively representing the upper level, lower level and base level (Kafarov 1976), respectively. Tables 1 and 2 are used to construct the coded design matrix in terms of $x_{j}$ and are given in table 3 .

The response function $y$ is given by the following linear regression equation,

$$
\begin{aligned}
y= & a_{0} x_{0}+a_{1} x_{1}+a_{2} x_{2}+a_{3} x_{3}+a_{12} x_{1} x_{2}+a_{13} x_{1} x_{3} \\
& +a_{23} x_{2} x_{3}+a_{123} x_{1} x_{2} x_{3},
\end{aligned}
$$

\begin{tabular}{|c|c|c|c|c|}
\hline \multicolumn{3}{|c|}{ Factors on dimensionless scale } & \multirow{2}{*}{$\begin{array}{c}\text { Dummy } \\
\text { variables } \\
x_{0}\end{array}$} & \multirow{2}{*}{$\begin{array}{c}\text { Fraction } \mathrm{NiCl}_{2} \\
\text { reduced } \\
y\end{array}$} \\
\hline$\overline{x_{1}}$ & $x_{2}$ & $x_{3}$ & & \\
\hline+1 & +1 & +1 & +1 & $0 \cdot 980$ \\
\hline+1 & -1 & +1 & +1 & 0.063 \\
\hline+1 & +1 & -1 & +1 & $0 \cdot 982$ \\
\hline+1 & -1 & -1 & +1 & 0.066 \\
\hline-1 & +1 & +1 & +1 & 0.577 \\
\hline-1 & -1 & +1 & +1 & $0 \cdot 013$ \\
\hline-1 & +1 & -1 & +1 & 0.634 \\
\hline-1 & -1 & -1 & +1 & 0.021 \\
\hline
\end{tabular}

Table 3. Coded design matrix.

where

$$
a_{j}, \text { for } j=0,1, \ldots 3,
$$

$$
a_{i j} \text {, for } i=1,2, j=i+1, \ldots .3 .
$$

The equations contain first order, second order interaction coefficients, respectively and $a_{123}$ is the third order interaction coefficient.

Using the data of table 3, interaction coefficients are evaluated by Kafarov (1976),

$$
\begin{aligned}
& a_{j}=1 / N \sum_{l=1}^{N} x_{l j} y \quad \text { for } j=1, \ldots 3, \\
& a_{i j}=1 / N \sum_{l=1}^{N} x_{i l} x_{j l} y \quad \text { for } i=1,2, j=i+1, \ldots 3, \\
& a_{i j k}=1 / N \sum_{l=1}^{N} x_{i l} x_{j l} x_{k l} y \quad \text { for } i=1, j=i+1, \\
& k=i+2,
\end{aligned}
$$

$N$ is the total number of experiments. In this case $N$ is equal to 8 . In order to find out significant coefficients, following student $t$ test was carried out.

$$
t_{j}=\frac{\left|a_{j}\right|}{S_{a j}},
$$

where $a_{j^{\prime} s}$ are interaction coefficients calculated by (4-6). $S_{a j}$, the estimated variance of coefficients are given by:

$$
S_{a j}=S_{\mathrm{e}} / \sqrt{ } N,
$$

where $S_{\mathrm{e}}$, the square root of error mean square given by

$$
S_{\mathrm{e}}^{2}=\frac{1}{2}\left[\sum_{i=1}^{3}\left\{y_{i}^{0}-\left(\sum_{l=1}^{3} y_{l}^{0} / 3\right)\right\}^{2}\right],
$$

$y_{i}^{0}$ is the yield of nickel at the base level for $i$ th replicate. Using the data of replicates at the base level (table 2), 
the computed $S_{\mathrm{e}}$ turns out to be $0 \cdot 0416$. Thus, using (7) along with (8) and (9), the ' $t$ ' values were calculated and is tabulated below:

$$
\begin{array}{ll}
t_{0}=28.36 & t_{12}=5 \cdot 57, \\
t_{1}=7 \cdot 19 & t_{13}=0 \cdot 51, \\
t_{2}=25.59 & t_{23}=0 \cdot 40, \\
t_{3}=0.59 \quad t_{123}=0.42 .
\end{array}
$$

The tabulated value of student $t$ distribution, $t_{\mathrm{p}}(f)$ is $4 \cdot 3$ for a significance value of $P=0.05$ and degree of freedom $f=2$. Comparing the computed $t$-values with $4 \cdot 3$, it was found that $t_{13}, t_{23}, t_{3}$ and $t_{123}$ values were less and hence, the corresponding coefficients are statistically insignificant in the regression equation (1). Thus regression equation containing only the significant interaction coefficients is given by:

$$
y=0 \cdot 417+0 \cdot 10575 x_{1}+0 \cdot 37625 x_{2}+0 \cdot 082 x_{1} x_{2},
$$

whether (10) is statistically adequate was tested by Fisher's variance ratio $(F)$ test which is given by

$$
F=S_{\mathrm{r}}^{2} / S_{\mathrm{e}}^{2},
$$

where $S_{\mathrm{e}}^{2}$ is the error mean square and has already been evaluated by (9).

$S_{\mathrm{r}}^{2}$ is the residual mean square and is given by:

$$
S_{\mathrm{r}}^{2}=\left\{\sum_{i=1}^{N}\left(\hat{y}_{i}-y_{i}\right)^{2}\right\} /(N-1),
$$

$\hat{y}_{i}$ and $y_{i}$ are the yield of nickel computed theoretically by (10) and experimentally obtained for $i$ th experiment, respectively. $l$ stands for the number of significant coefficient. The value of $l$ as obtained from student $t$ test is 4 . Using table 3 , (10) and (12), the ratio $F$ computed by (11) is $0 \cdot 24$. For significance level of $p=0.05$, and for degrees of freedom $f_{1}=$ $N-l=8-4=4$ and $f_{2}=2$, the tabulated value of $F_{0.05}(4,2)$ is $19 \cdot 3$ (Grewall 1998).

Since, $F<F_{0.05}(4,2)$, the estimated regression equation is statistically adequate. To test the validity of (10) independently a point $x_{1}=0.5, x_{2}=0.5$ was taken in the design space. The experiment was replicated thrice and the experimental fraction conversions were $0.82,0.87$ and 0.77 , respectively. Based on these data, the calculated $F(4,2)=0.18$ which is less than the theoretical $F_{0.05}=19 \cdot 3$. This shows that the predicted value by the regression equation is within 95\% confidence limit.

The statistically adequate regression (10) is linear. It is, therefore, expected that the maximum fraction reduction of $\mathrm{NiCl}_{2}$ occurs at the design boundary. From (10), the maximum predicted yield of $\mathrm{Ni}$ is found to be 0.981 for $x_{1}=1$ and $x_{2}=1$, which is in excellent agreement with the experimentally observed yield of 0.982 for $x_{1}=1$ and $x_{2}=1$ (table 3 ).
This means that maximum reduction occurs when the sample is heat treated at the highest temperature of $900{ }^{\circ} \mathrm{C}$ for longest time of $8 \mathrm{~min}$ for this particular design space under consideration and this is what is expected from the kinetic point of view.

\section{Conclusions}

(I) A statistically adequate regression equation as a function of reduction temperature and time is developed by the design of experiment.

(II) With the increase of reduction temperature and time the yield of metallic Ni increases.

(III) The maximum yield of nickel is obtained at the maximum temperature of reduction of $900{ }^{\circ} \mathrm{C}$ and the time of 8 min.

\section{Acknowledgements}

The authors acknowledge Mr Sudhir Ghosh, School of Materials Science and Nanotechnology, for taking XRD patterns.

\section{References}

Aldal J, Rico-Gracia J M, Lopez-Alonso J M and Boreman S 2005 Nanotechnology 16230

Basumallick A, Das G C and Mukherjee S 1999 Thermochim. Acta 325167

Cullity B D 1978 Elements of X-ray diffraction (Reading, Mass: Addison-Wesley)

Das G C, Basumallick A and Mukherjee S 1990 Bull. Mater. Sci 13 255

Fonseca F C 2003 Appl. Phys. A: Mater. Sci. Processing 76621

Gao Y Q and Bando Y 2002 Nature 415599

Gorla C R, Emanetoglu N W, Liang S, Mago W E, Lu Y, Wraback M and Shen M 1999 J. Appl. Phys. 852595

Granquivst G C and Hunderi O 1977 Phys. Rev. B 163513

Grewall B S 1998 Higher engineering mathematics (New Delhi: Khanna Publications)

Kafarov V 1976 Cybernetic methods in chemistry and chemical engineering (Moscow: Mir Publication)

Mallick S, Das G C, Mukherjee S and Mitra M K 2006 J. Phys. Chem. Solids 671792

Peng K, Zhou Lingping, Hu Aiping, Tang Yuanhong and Deyi Li 2008 Mater. Chem. Phys. 334

Rao C N R 1993 Mater. Sci. Eng. B18 1

Roy S K, Dey R, Mitra A, Mukherjee S, Mitra M K and Das G C 2007 Mater. Sci. Engg. C 27725

Tang N J, Zhong W, Liu W, Jiang H Y, Wu X L and Du Y W 2004 Nanotechnology 151756

Warren B E and Biscal J 1938 Am. J. Ceram. Soc. 2149

Yeshchenko, Oleg A, Dmitruk, Igor M, Alexeenko, Alexandr A, Dmytruk and Andriy M 2008 J. Phys. Chem. Solids 691615 